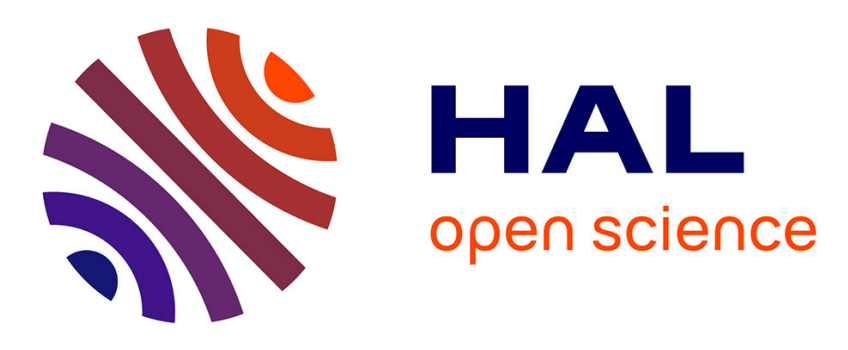

\title{
Numerical simulation of the response of a reinforced wall to a high speed train passage
}

Alain Corfdir, Emmanuel Bourgeois, Jean-Baptiste Payeur

\section{To cite this version:}

Alain Corfdir, Emmanuel Bourgeois, Jean-Baptiste Payeur. Numerical simulation of the response of a reinforced wall to a high speed train passage. International Journal for Numerical and Analytical

Methods in Geomechanics, 2017, 41 (11), pp.1283-1346. 10.1002/nag.2674 . hal-01475941v3

\section{HAL Id: hal-01475941 \\ https://hal.science/hal-01475941v3}

Submitted on 20 Oct 2017

HAL is a multi-disciplinary open access archive for the deposit and dissemination of scientific research documents, whether they are published or not. The documents may come from teaching and research institutions in France or abroad, or from public or private research centers.
L'archive ouverte pluridisciplinaire HAL, est destinée au dépôt et à la diffusion de documents scientifiques de niveau recherche, publiés ou non, émanant des établissements d'enseignement et de recherche français ou étrangers, des laboratoires publics ou privés. 


\section{Numerical simulation of the response of a reinforced wall to a high speed train passage}

A. Corfdir, E. Bourgeois, J.-B. Payeur

A. Corfdir

Université Paris-Est, Ecole des Ponts ParisTech

6-8 av Blaise Pascal, F-77455 Champs sur Marne

corfdir@cermes.enpc.fr

tel: 33 (0)1 64153521 ; fax: $33(0) 164153562$

E. Bourgeois

Université Paris-Est, IFSTTAR-COSYS

14-20 bd Newton, F-77420 Champs sur Marne

emmanuel.bourgeois@ifsttar.fr

J.-B. Payeur

CEREMA/Direction Territoriale Méditerranée/Service RGGC/Unité géotechnique

jean-baptiste.payeur@cerema.fr 


\begin{abstract}
The dynamic response of a mechanically stabilized earth wall to the passing of a high speed train is modelled using the finite element method. A three-dimensional analysis is carried out, using a specific framework that allows performing the analysis with a moderate computational effort. In the first place, a so-called multiphase approach is used to take into account the reinforcing strips. The moving load is taken into account by performing the calculation in a mobile referential using the properties of symmetry of the train cars and a simplifying assumption of periodicity for the whole train. We also assume a steady state. A partial validation of the approach is obtained by means of a comparison with an analytical solution. The quick increase in displacements induced by the train passing when the speed comes close to the celerity of Rayleigh wave clearly appears in the results. The vertical displacements, vertical stresses in the backfill, tensile forces in the strips and the influence of the stiffness of the soil are discussed.
\end{abstract}

Keywords: FEM, reinforced earth, high speed train, mobile referential, multiphase model

\title{
1 Introduction
}

Reinforced Earth walls, or Mechanically Stabilized Earth Walls (MSE walls), are geotechnical structures often used to build retaining walls, bridge abutments, road embankments, etc. They have been first developed in France by Henri Vidal in the 1960s (1), and have been introduced in the United States some years later (2). They consist in an association (3) of well-chosen backfill material and reinforcing strips (generally made of steel, even if synthetic materials are increasingly used) attached to a facing wall usually composed of concrete panels (Figure 1). In addition of its cost efficiency and ease of implementation, this technique makes it possible to realize "vertical slopes" of backfill, leading to a consequent gain in space. These advantages explain the rapid spread of the technique over the last 
decades. However, such structures are rarely used for high speed railways embankments and their response to the dynamic loads associated with the passage of a high speed train is not well known.

The usual design does not rely on FEM methods ( (4), (5), (6)), however, a number of researchers have used FEM modelling, first in 2D (e.g. (7)), then 3D calculations. FEM modelling meets a challenge: the presence of the reinforcing strips. The number of reinforcing strips implies a lot of work to prepare the mesh and a large number of elements with very different sizes. Another particular concern is the modelling of the interface between soil and reinforcing strips. Special interface elements have been introduced to simulate the interface behaviour ((8), (9)). Homogenization methods have also been introduced for limit analysis (10) or for elastic behaviour modelling (11) (12) (13). The introduction of multiphase model allows to combine homogenization and the modelling of the interface (14) (15). This model has been successfully used for the simulation of various types of geotechnical structures under static loadings, such as piled raft foundations (16) (17), MSE walls (18) (19), etc. More recently, the possibilities of the approach under dynamic loadings have been investigated by Nguyen et al. (20).

The FEM modelling of the effect of dynamic loads on soils implies that specific procedures must be used to avoid unrealistic reflections of waves on the boundaries of the analyzed domain. This may be done by taking into account a numerical domain much larger than the height of the embankment and the length of the train or by the use of more advanced techniques, such as infinite elements (21), absorbing boundaries (22) or coupling of finite elements and boundary elements (23) (24) but such approaches remain difficult to use.

In a former paper (25), we have investigated the dynamic behaviour of such a structure subjected to a harmonic load applied on a fixed place, and compared the results of dynamic finite element simulations with the results obtained on an experimental wall (26).

However, a train is a moving load. The use of a referential attached to a mobile load in motion over a railway is well described in the literature (27) (28). From a geotechnical point of view, such approaches are mainly aiming at the evaluation of the ground surface settlement under the load, even if the approach is also used to investigate the ground/carriage interaction by means of mass/spring models. The velocity of the load is generally constant (28) (29) and its amplitude can be constant or harmonic (30) (31). The ground layer is represented by a semi-infinite domain, with a behavior either elastic (32), visco-elastic 
(32) (33), or poroelastic (34). It is generally accepted that this approach makes it possible to take into account the influence of the load velocity on the ground surface displacements, which becomes large as the train velocity gets close to the velocity of Rayleigh waves (see for instance (31)).

The FEM or BEM-FEM direct simulation in the time domain is possible (35) but it needs to model a large volume of soil. Assuming that the geometry and the mechanical properties of the system are invariant along the direction of the track makes it possible to use the so-called $2.5 \mathrm{D}$ simulations which uses a Fourier transform in the direction of the track (36) (37).

The aim of the present paper is to evaluate the behaviour under the vertical load generated by a moving train in the specific case of reinforced earth. Our approach aims at combining the use of a mobile referential, the use of multiphase modelling and the use of specific boundary conditions taking into account of the periodicity of the load, under some simplifying assumptions, like steady-state and spatial periodicity of the load.

\section{Modelling assumptions}

\subsection{Outline}

Let us consider a train moving on a railway built over a Mechanically Stabilized Earth wall. As the train moves along the railway, the load associated to a train axle induces displacements and strains in the structure beneath the railway, while stresses in the embankment and forces in the strips vary. Our aim is to investigate these variations of stresses and strains in the reinforced structure, for one single passage of the train (long term effects due to the possible fatigue of the MSE wall are not taken into account here).

The complexity of the problem arises from numerous sources:

- The railway itself is a complex system, due to its geometry - the discrete distribution of the sleepers for instance - and to the behavior of its components, the ballast being a highly nonlinear and discontinuous material (see for example (38)) 
- The MSE wall below the railway has the structure of a heterogeneous composite material made of the backfill material and the discontinuously distributed reinforcement strips. Moreover, the strips have a cross section of very small transversal dimensions compared with their length and the mechanical interaction between the embankment material and the strips involves complex friction phenomena.

- The load coming from the train is applied in a series of points corresponding to the location of the wheels, making the problem three-dimensional.

- The displacement of the load at a high speed induces dynamic effects in the reinforced structure: from a numerical point of view it is necessary to pay attention to boundary conditions specially to avoid unrealistic wave reflections.

For all these reasons, it is advisable to adopt a set of simplifying assumptions in order to discuss the behavior of MSE walls used as support for a high speed railway.

\subsection{Assumption of steady-state regime and use of a mobile referential}

We assume the railway is rectilinear and horizontal, parallel to direction $\mathrm{x}$, and the train velocity $\mathrm{v}$ is constant. Under these assumptions, we postulate that it is possible to reach a steady state regime and to study the response of the wall in a mobile referential attached to the train. This requires that the geometry and the material properties of the railway and the MSE wall are invariant along the direction of the train motion: this assumption is obviously valid for the rails, and can be sustained for the wall facing, but it is clearly not correct for the sleepers, for instance, nor for the steel strips constituting the MSE wall, because they are discontinuous in the direction of the motion.

\subsection{Load and the strip reinforced backfill modeling}

The sleepers are not taken into account in the model, but instead, the loads transmitted by the rails and the sleepers to the ballast layer are represented by equivalent distributions of pressures applied directly at the top of the ballast layer (Figure 2). 
The steel strips of the MSE wall are parallel to the direction y. To overcome the difficulty induced by the discontinuous distribution of the strips, we replace the reinforced bulk of ground by a homogeneous "equivalent" material. Since it is generally acknowledged that the strip-backfill interaction is of crucial importance to account for the behaviour of MSE walls under static loading, special attention is paid in section 4 hereafter to the choice of this homogeneous material.

\section{Analysis of the problem in the referential attached to the train}

Within this framework, the basic assumption we formulate is that the value of all quantities, at a given point $\mathrm{x}$ and at time $\mathrm{t}$, are equal to the value taken at point $x^{\prime}=x-v t$ at time $0, v$ denoting the velocity of the train:

$$
f(x, y, z, t)=f\left(x^{\prime}=x-v t, y, z, 0\right)
$$

In other words, time can be seen as a parameter and (1) can be rewritten as:

$$
f(x, y, z, t)=F\left(x^{\prime}, y, z\right)
$$

with the convention that capital letters refer to fields defined in the referential attached to the train (and therefore independent on time). This approach is similar to that adopted for instance by Zhai and Song (33) who introduce the notion of "moving coordinates" and of finite element method in moving coordinates (MFEM). Note however that the problem discussed here is simpler, because of the assumption of steady-state regime.

We introduce a reference configuration, in which displacements, velocities and accelerations are zero. In this configuration, the stress tensor in the ground is denoted by $\sigma$. During the passage of a train, the stress field shows variations with respect to the reference situation, denoted by $\delta \sigma$. In a fixed referential, at a given point $x$, the momentum balance equation reads:

$$
\operatorname{div} \delta \sigma-\rho \gamma=0
$$

where $\gamma$ denotes the ground acceleration. According to the assumptions above, the loads brought by the train are represented by distributions of pressure applied at the top the embankment. Denoting by $n$ the 
outward normal unit vector on the upper surface of the domain, the surface force density $p=\delta \sigma . \mathrm{n}$ is given by:

$$
p=-q(x, y, z, t) n,
$$

where $q(x, y, z, t)$ describes both the distribution of the loads transmitted from the axles to the ground through the ballast layer and its variations as the train passes. The boundary conditions will be discussed later.

It is readily seen from Eq. (1) that

$$
\operatorname{div} \delta \sigma(x, y, z, t)=\operatorname{div} \delta \sigma\left(x^{\prime}=x-v t, y, z, 0\right)=\operatorname{div} \delta \Sigma\left(x^{\prime}, y, z\right) .
$$

where $\delta \Sigma$ denotes the stress tensor written with the variables of the mobile referential.

It follows from Eq. (1) that the displacement field $u(x, y, z, t)$ and its derivatives can be deduced from their counterpart in $\left(x^{\prime}, y, z\right)$ at time 0 :

$$
u(x, y, z, t)=U\left(x^{\prime}=x-v t, y, z\right) \rightarrow \gamma(x, y, z, t)=v^{2} \frac{\partial^{2} U}{\partial x^{\prime 2}}\left(x^{\prime}, y, z\right) .
$$

Introducing (6) in (5) yields:

$$
\operatorname{div} \delta \Sigma\left(x^{\prime}, y, z\right)-\rho v^{2} \frac{\partial^{2} U}{\partial x^{2}}\left(x^{\prime}, y, z\right)=0
$$

Assuming the ground behavior is linear elastic with no damping, the stress variation is related to the strain $\varepsilon$ by:

$$
\delta \sigma(x, y, z, t)=C(x, y, z) \varepsilon(x, y, z, t)
$$

where $C$ is the elastic moduli tensor and $\varepsilon$ the symmetric part of the gradient of the displacement. Eventually, we introduce the assumption that the material properties of all parts of the system are invariant along the direction of motion:

$$
C(x, y, z)=C(y, z) ; \rho(x, y, z)=\rho(y, z) .
$$

This condition does not require that the domain is isotropic or homogeneous (variations of the elastic moduli with depth for instance are allowed). 


\subsection{Variational formulation}

Multiplying Eq. (7) by a virtual displacement field $U^{\prime}$, and integrating over the domain $\Omega$ taken into account in the analysis (which remains to be defined precisely at that stage, but does not depend on time), we obtain:

$$
\int_{\Omega}\left[U^{\prime} \cdot \operatorname{div} \delta \Sigma-\rho v^{2} U^{\prime} \cdot \frac{\partial^{2} U}{\partial x^{2}}\right]=0 .
$$

where the dot denotes the inner product of two vectors, and the differential element has been omitted for the sake of simplicity. Using the constitutive law and a classical integration by parts, one gets

$$
\int_{\Omega}\left[\varepsilon: C: \varepsilon^{\prime}-\rho v^{2} \frac{\partial U^{\prime}}{\partial x} \cdot \frac{\partial U}{\partial x}\right]=\int_{\partial \Omega}\left[P \cdot U^{\prime}-\rho v^{2} \frac{\partial}{\partial x}\left(U^{\prime} \cdot \frac{\partial U}{\partial x}\right)\right]
$$

where $\mathrm{n}$ is the outward normal unit vector on the boundary $\partial \Omega$ of the domain $\Omega$ and $\mathrm{P}=\delta \Sigma$. $\mathrm{n}$ is the surface density of force acting on $\partial \Omega$ (that is the force acting per unit area). It must be emphasized that the above equation is valid only if the first derivative of the displacement field $\frac{\partial U}{\partial x}$ is continuous, which excludes the case of a shock wave.

\subsection{Boundary conditions and loads}

This section is devoted to the discussion of the boundary integral

$-\rho v^{2} \int_{\partial \Omega}\left[\frac{\partial}{\partial x}\left(U^{\prime} \cdot \frac{\partial U}{\partial x}\right)\right]$

that has been introduced by the integration by parts above. In what follows, we introduce a new set of assumptions, under which this term vanishes. We assume that the train is of infinite length, and made of a succession of similar train cars, so that its action on the embankment can be represented by a set of forces applied on its upper boundary and periodically distributed along the direction of the motion. The spatial period of the applied loads is typically equal to the length of each car.

Under these assumptions, the domain taken into account in the analysis can be limited to the half-length of a train car, and the vertical planes $\Pi_{1}$ and $\Pi_{2}$ of Figure 3 are clearly planes of symmetry, one corresponding to the middle of each bogie, and the other to the middle of each car. Thus, we limit the domain taken into account in the study to the interval between the planes $\Pi_{1}$ and $\Pi_{2}$ of the figure, and 
we denote by $S_{\text {top }}$ and $S_{\text {bottom }}$ its upper and lower boundaries. The loads brought by the train are taken into account through surface densities of vertical forces applied on specific areas of $\mathrm{S}_{\text {top }}$, denoted by $\mathrm{P}$ and represented by arrows in Figure 3.

The following holds for each point of $\Pi_{1}$ and $\Pi_{2}$ :

$$
\begin{aligned}
& U_{x}=0 \\
& \sigma_{y x}=\sigma_{z x}=0 .
\end{aligned}
$$

It is natural to choose $U^{\prime}$ among the virtual displacement fields that satisfy the first condition, i.e such that

$$
U^{\prime}{ }_{x}=0 \text { on } \Pi_{1} \text { and } \Pi_{2}
$$

Besides, if all the materials constituting the structure are isotropic, the shear strains are zero:

$$
\varepsilon_{y x}=\varepsilon_{z x}=0
$$

and then

$$
\frac{\partial U_{y}}{\partial x}=\frac{\partial U_{z}}{\partial x}=0
$$

Using Eq. (15) and Eq. (17), the integral Eq.(12) vanishes and the weak form of the problem reduces to

$$
\int_{\Omega} \varepsilon: C: \varepsilon^{\prime}-\int_{\partial \Omega} \rho v^{2} \frac{\partial U^{\prime}}{\partial x} \cdot \frac{\partial U}{\partial x}=\int_{\partial \Omega} \quad P \cdot U^{\prime} .
$$

In other words, the train velocity introduces a bilinear form in the left hand side, which has a structure very similar to the first part of the left hand side: both involve products of the spatial derivatives of $U$ and $U^{\prime}$.

\section{Case of a multiphase model}

\subsection{Application of the multiphase modelling method}

The discontinuous distribution of the strips in the MSE wall along the direction of the motion does not normally allow formulating the problem in the mobile referential, because Eq. (9) is not satisfied. TO overcome this difficulty, we resort to the so-called multiphase model, described in (14) and (15). 
According to this model, the reinforced soil is schematized as a two-phase system, which represents the superposition of two continuous media, called matrix and reinforcement phases. In the case of MSE walls, the matrix phase represents the backfill material and the reinforcement phase represents, in a global manner, the steel strips. Each phase is associated with a displacement field denoted by $\mathrm{u}^{\mathrm{m}}$ for the matrix and $\mathrm{u}^{\mathrm{r}}$ for the reinforcement. The momentum balance equations, expressed for each phase separately, may be written as:

$$
\begin{aligned}
& \operatorname{div} \delta \sigma^{m}+I=\rho^{m} \frac{\partial^{2} u^{m}}{\partial t^{2}} \\
& \operatorname{div}\left(\delta n^{r} e_{y} \otimes e_{y}\right)-I=\rho^{r} \frac{\partial^{2} u^{r}}{\partial t^{2}}
\end{aligned}
$$

where gravity forces are neglected, and $\rho^{m}$ and $\rho^{r}$ denote the volume densities of the phases. In the above equations $n^{r}$ denotes the density of axial force in the reinforcement phase (i.e. the axial force per unit area) in a plane perpendicular to the reinforcement orientation $\mathrm{e}_{y}$. This density is equal to the normal effort $N$ in one reinforcing strip divided by the area $A$ of facing wall associated with each strip:

$$
n^{r}=\frac{N}{A}
$$

In terms of variations with respect to the reference configuration (corresponding to the end of the wall construction) Eq. (21) can be written as:

$$
\delta n^{r}=\frac{\delta N}{A}
$$

Besides, in the above Eqs (19) and (20), I is the (volume density of) interaction force exerted by the reinforcement phase on the matrix phase. Following (20), we neglect the inertia term of the second dynamic equilibrium equation, so that the interaction force density $I$ is oriented along the reinforcement direction: $I=I \mathrm{e}_{y}$.

The constitutive laws of the phases are expressed as:

$$
\begin{aligned}
& \delta \sigma^{m}=C^{m}: \varepsilon^{m} \text { for the matrix phase } \\
& \delta n^{r}=\alpha^{r} \varepsilon^{r} \text { for the reinforcement phase, }
\end{aligned}
$$

where the strain variables $\varepsilon_{\mathrm{m}}$ and $\varepsilon_{\mathrm{r}}$ are defined from the displacement fields as: 


$$
\varepsilon^{m}=\frac{1}{2}\left(\operatorname{grad} u^{m}+{ }^{t} \operatorname{gradu} u^{m}\right) \text { and } \varepsilon^{r}=\frac{\partial u_{y}^{r}}{\partial y} .
$$

$C^{m}$ stands for the tensor of elastic moduli of the matrix phase and $\alpha^{\mathrm{r}}$ is the axial stiffness of the reinforcement phase.

The interaction force may be chosen by adopting a constitutive law which linearly links the interaction force density I to the difference between the displacements of the two phases along the reinforcement orientation:

$$
I=c^{I}\left(u_{y}^{m}-u_{y}^{r}\right)
$$

In a similar way to (20), the parameters of the model are chosen as follows: the elastic moduli of the matrix phase are assumed to be equal to those of the original (unreinforced) backfill material, while the axial stiffness of the reinforcement phase is calculated as:

$$
\alpha^{r}=\eta E
$$

where $\eta$ is the volume fraction of the strips and $E$ the steel Young's modulus . Similarly, we assume the matrix phase volume density can be taken equal to the backfill material volume density and the reinforcement phase volume density is equal to $\eta$ times the volume density of steel.

The identification of the interaction stiffness parameter $c^{I}$ appearing in Eq (26) is discussed, in the case of piled raft foundations in (16), (39). We adopt here the value proposed for a MSE wall in (18), assuming the stiffness interaction parameter $c^{I}$ does not depend on the frequency, which can be backed up by (20).

We summarize here the assumptions:

- The reference configuration of the model corresponds to the end of the MSE wall construction; it includes gravity loads. Our dynamical calculations consider only the changes with respect to this reference configuration under the moving load.

- We consider a multiphase model with two phases: matrix (soil) and reinforcement (steel strip).

- We assume a linear behavior of matrix, reinforcement and matrix/reinforcement interaction. 
- We neglect the inertia term associated with the reinforcement phase.

\subsection{Boundary conditions}

This section presents the generalization of the discussion about the boundary conditions when the MSE wall is modeled using the multiphase approach, under the same set of assumptions as before: train of infinite length, applying pressures on the ground periodically distributed along the direction of the motion, domain limited to the half-length of a car.

The equations (19) and (20) now read:

$$
\begin{aligned}
& d i v \delta \sigma^{m}+I e_{y} y-\rho \gamma=0, \\
& \frac{\partial \delta n^{r}}{\partial y}-I=0
\end{aligned}
$$

with the constitutive relations Eq.(23) and Eq.(24). Writing (28) in the mobile referential, we obtain the relation similar to (7):

$$
\operatorname{div} \delta \sigma^{m}+I e_{y}-\rho v^{2} \frac{\partial^{2} U}{\partial x^{2}}\left(x^{\prime}, y, z\right)+I_{s} e_{y}=0
$$

where $I_{s}$ is a surface density of force that can be exerted, in the y direction, by the strips on the boundary of the reinforced zone (the equation being understood in the sense of distributions, see (20) ). This makes it possible to take into account for instance the mechanical connection of the strips on the wall facing panels; on the contrary, we assume that the density of axial force in the reinforcement phase is zero at the free end of the strips. Multiplying Eq.(27) by a virtual displacement field $U^{\prime m}$, we get:

$$
\int_{\Omega}\left[U^{\prime} \cdot \operatorname{div} \delta \Sigma^{m}-\rho v^{2} U^{\prime m} \cdot \frac{\partial^{2} U^{m}}{\partial x^{2}}\right]+\int_{\Omega}\left[U_{y}^{\prime m} I\right]+\int_{\text {facing }}\left[U_{y}^{\prime m} I_{S}\right]=0
$$

Performing an integration by parts and introducing the constitutive law of the matrix phase leads to transform the previous equation into:

$\int_{\Omega}\left[\varepsilon^{m}: C^{m}: \varepsilon^{\prime}-\rho v^{2} \frac{\partial U^{\prime m}}{\partial x} \cdot \frac{\partial U^{m}}{\partial x}\right]=\int_{\Omega}\left[U_{y}^{\prime m} I\right]+\int_{\text {facing }}\left[U_{y}^{\prime m} I_{S}\right]+\int_{\partial \Omega} P \cdot U^{\prime m}=0$.

Multiplying the momentum balance equation for the reinforcement phase Eq. (29) by a virtual field $U^{\prime r}$ and integrating over the area in which the reinforced ground is modeled as a multiphase material $\Omega_{\mathrm{r}}$, one gets: 


$$
\int_{\Omega_{r}} U_{y}^{\prime r}\left[\frac{\partial n_{r}}{\partial y}-I\right]=0
$$

An integration by parts and the constitutive equation of the reinforcement phase lead to:

$$
\int_{\Omega_{r}} U_{y}^{\prime r}\left[\frac{\partial n_{r}}{\partial y}\right]=\int_{\Omega_{r}} \frac{\partial\left(U^{\prime} r_{y}^{r} n_{r}\right)}{\partial y}-\int_{\Omega_{r}} \frac{\partial U_{y}^{\prime r}}{\partial y} \alpha^{r} \frac{\partial U_{y}^{r}}{\partial y}
$$

Assuming the stress in the reinforcement phase (i.e. the traction forces in the strips) is zero at the boundary corresponding to the free end of the strips $\left(y=L_{s}\right.$ in Figure 2), and taking advantage of the fact that the displacement of the matrix and the reinforcement phase are equal for $y=0$ (where the strips are connected to the facing), we get:

$$
\int_{\Omega_{r}} U_{y}^{\prime r}\left[\frac{\partial n_{r}}{\partial y}\right]=\int_{\text {facing }} U_{y}^{\prime r} T_{s}-\int_{\Omega_{r}} \frac{\partial U_{y}^{\prime r}}{\partial y} \alpha^{r} \frac{\partial U_{y}^{r}}{\partial y}
$$

where $T_{s}$ is the surface density of force acting on the reinforcement phase. Combining Eqs (32), (33) and (35), and introducing (23), we eventually obtain:

$\int_{\Omega} \epsilon^{m}: C^{m}: \epsilon^{\prime}-\rho v^{2} \int_{\Omega}\left[\frac{\partial U^{\prime m}}{\partial x} \cdot \frac{\partial U^{m}}{\partial x}\right]+\int_{\Omega_{r}} \frac{\partial U_{y}^{\prime r}}{\partial y} \alpha^{r} \frac{\partial U_{y}^{r}}{\partial y}+\int_{\Omega_{r}}\left(U_{y}^{r}-U_{y}^{m}\right) c^{I}\left(U_{y}^{\prime r}-U_{y}^{\prime m}\right)=$

$\int_{\partial \Omega} P \cdot U^{\prime m}$

With respect to the classical monophasic situation, the variational formulation above introduces two additional bilinear symmetric forms, corresponding to the last two terms of the left hand side. Their numerical treatment does not rise specific difficulties and has been carried out before, for instance in (16), (17), (18) or (19).

\section{Numerical implementation}

\subsection{Modification of the stiffness matrix}

As pointed out before, the additional term that depends on the velocity has the same structure as the terms associated with the elastic moduli. From a numerical point of view, the additional term has the same structure as the stiffness matrix, and results from the integration of products of shape functions derivatives. Consequently, its computation in the framework of a finite element code is relatively 
straightforward. We denote by $\mathrm{k}$ the number of nodes of an element, and by $\{q\}=\left\{u_{x}^{1}, u_{x}^{2}, \ldots u_{x}^{k}, u_{y}^{1}, u_{y}^{2}, \ldots u_{y}^{k}, u_{z}^{1}, u_{z}^{2}, \ldots u_{z}^{k}\right\}$ the nodal displacements vector of the element, by $\mathrm{N}_{\mathrm{i}}$ the shape function equal to 1 on node $i$ and 0 on the other nodes.

We define the usual matrices $\mathrm{L}$ and $\mathrm{N}^{\mathrm{e}}$ by:

$$
\begin{aligned}
L & =\left[\begin{array}{ccc}
\frac{\partial}{\partial x} & 0 & 0 \\
0 & \frac{\partial}{\partial y} & 0 \\
0 & 0 & \frac{\partial}{\partial z} \\
\frac{\partial}{\partial y} & \frac{\partial}{\partial x} & 0 \\
0 & \frac{\partial}{\partial z} & \frac{\partial}{\partial y} \\
\frac{\partial}{\partial z} & 0 & \frac{\partial}{\partial x}
\end{array}\right] \\
N^{e} & =\left[\begin{array}{cccccccccccc}
N_{1} & N_{2} & \ldots & N_{\mathrm{k}} & 0 & 0 & \ldots & 0 & 0 & 0 & \ldots & 0 \\
0 & 0 & \ldots & 0 & N_{1} & N_{2} & \ldots & N_{\mathrm{k}} & 0 & 0 & \ldots & 0 \\
0 & 0 & \ldots & 0 & 0 & 0 & \ldots & 0 & N_{1} & N_{2} & \ldots & N_{\mathrm{k}}
\end{array}\right]
\end{aligned}
$$

The strains can be computed by:

$$
\begin{gathered}
\{\varepsilon\}=B^{e}\{q\} \text { with } B^{e}=L \cdot N^{e} \\
B^{e}=\left[\begin{array}{ccccccccccccc}
\frac{\partial N_{1}}{\partial x} & \frac{\partial N_{2}}{\partial x} & \ldots & \frac{\partial N_{k}}{\partial x} & 0 & 0 & \ldots & 0 & 0 & 0 & \ldots & 0 \\
0 & 0 & \ldots & 0 & \frac{\partial N_{1}}{\partial y} & \frac{\partial N_{2}}{\partial y} & \ldots & \frac{\partial N_{k}}{\partial y} & 0 & 0 & \ldots & 0 \\
0 & 0 & \ldots & 0 & 0 & 0 & \ldots & 0 & \frac{\partial N_{1}}{\partial z} & \frac{\partial N_{2}}{\partial z} & \ldots & \frac{\partial N_{k}}{\partial z} \\
\frac{\partial N_{1}}{\partial y} & \frac{\partial N_{2}}{\partial y} & \ldots & \frac{\partial N_{k}}{\partial y} & \frac{\partial N_{1}}{\partial x} & \frac{\partial N_{2}}{\partial x} & \ldots & \frac{\partial N_{k}}{\partial x} & 0 & 0 & \ldots & 0 \\
0 & 0 & \ldots & 0 & \frac{\partial N_{1}}{\partial z} & \frac{\partial N_{2}}{\partial z} & \ldots & \frac{\partial N_{k}}{\partial z} & \frac{\partial N_{1}}{\partial x} & \frac{\partial N_{2}}{\partial x} & \ldots & \frac{\partial N_{k}}{\partial x} \\
\frac{\partial N_{1}}{\partial z} & \frac{\partial N_{2}}{\partial z} & \ldots & \frac{\partial N_{k}}{\partial z} & 0 & 0 & \ldots & 0 & \frac{\partial N_{1}}{\partial x} & \frac{\partial N_{2}}{\partial x} & \ldots & \frac{\partial N_{k}}{\partial x}
\end{array}\right]
\end{gathered}
$$

The elementary stiffness matrix is given by:

$$
\int_{e}{ }^{t} B^{e} \cdot E \cdot B^{e}
$$

where $\mathrm{E}$ denotes the usual (local) elastic matrix. To compute the additional term introduced by the use of mobile referential, we introduce the differential operator L': 


$$
L^{\prime}=\left[\begin{array}{ccc}
\frac{\partial}{\partial x} & 0 & 0 \\
0 & \frac{\partial}{\partial x} & 0 \\
0 & 0 & \frac{\partial}{\partial x}
\end{array}\right]
$$

And we now set $\mathrm{G}^{\mathrm{e}}=\mathrm{L}^{\prime}$. $\mathrm{N}^{\mathrm{e}}$ :

$$
G^{e}=\left[\begin{array}{cccccccccccc}
\frac{\partial N_{1}}{\partial x} & \frac{\partial N_{2}}{\partial x} & \ldots & \frac{\partial N_{k}}{\partial x} & 0 & 0 & \ldots & 0 & 0 & 0 & \ldots & 0 \\
0 & 0 & \ldots & 0 & \frac{\partial N_{1}}{\partial x} & \frac{\partial N_{2}}{\partial x} & \ldots & \frac{\partial N_{k}}{\partial x} & 0 & 0 & \ldots & 0 \\
0 & 0 & \ldots & 0 & 0 & 0 & \ldots & 0 & \frac{\partial N_{1}}{\partial x} & \frac{\partial N_{2}}{\partial x} & \ldots & \frac{\partial N_{k}}{\partial x}
\end{array}\right]
$$

The correction of the stiffness matrix is then given by $-\rho v^{2} \int_{e}{ }^{t} G^{e} G^{e}$. In the framework of the multiphase model, it only concerns the matrix phase, since we have assumed that inertia terms in the reinforcement phase are negligible.

From a global point of view, the apparent stiffness is modified, and, if the velocity of the train becomes large enough, the stiffness matrix may no longer be definite and positive (in this case, discontinuities may appear in the velocity stress field and the above equations no longer hold). This is the explanation of the changes which appear in the results when the speed of the load approaches the velocity of Rayleigh wave (see results of section 5.2: the analytical and the numerical results become large when the speed approaches the velocity of Rayleigh waves, and both the analytical and the numerical computations are no longer possible for this speed).

\subsection{Elements of validation}

It is possible to validate partially the numerical implementation of the mobile referential approach, on the basis of analytical solutions provided, for a unique point load acting on an elastic half space, moving at velocity $\mathrm{v}$ along the $\mathrm{x}$-direction. The load being applied at point 0 (40) (a slightly earlier reference is (41)) gives the possibility to compute the vertical displacement $\mathrm{w}_{\mathrm{o}}(\mathrm{z})$ of a point located just below the $\mathrm{x}$-axis, at a depth $\mathrm{z}$

$$
w_{0}(x, y=0, z)=\frac{1}{4 \pi^{2}} \frac{P z}{\mu} \int_{0}^{\pi} \frac{H}{J}\left(\psi_{1}+\psi_{2}\right) d \varphi
$$

Where: 


$$
\begin{aligned}
& J=-\frac{m^{2}}{16}\left(M_{t}^{6} \cos ^{6} \varphi-8 M_{t}^{4} \cos ^{4} \varphi+8 M_{t}^{2} \cos ^{2} \varphi\left(3-\frac{2}{m^{2}}\right)-16+\frac{16}{m^{2}}\right) \\
& H=\left(1-\frac{1}{2} M_{t}^{2} \cos ^{2} \varphi\right)^{2}+\left(1-\frac{1}{m^{2}} M_{t}^{4} \cos ^{4} \varphi\right)^{1 / 2} \\
& \psi_{1}=\frac{z^{2}\left(1-\frac{1}{m^{2}} M_{t}^{4} \cos ^{4} \varphi\right)^{1 / 2}\left(m^{2}-1\right)}{\left(x^{2} \cos ^{2} \varphi+z^{2}\left(1-\frac{1}{m^{2}} M_{t}^{2} \cos ^{2} \varphi\right)\right)\left(x^{2} \cos ^{2} \varphi+z^{2}\left(1-M_{t}^{2} \cos ^{2} \varphi\right)\right)} \\
& \psi_{2}=\frac{\left(1-\frac{1}{m^{2}} M_{t}^{2} \cos ^{2} \varphi\right)^{1 / 2}\left(1-M_{t}^{2} \cos ^{2} \varphi\left(1+\frac{m^{2}}{4}\right)+\frac{1}{4} M_{t}^{4} \cos ^{4} \varphi\right)}{\left(x^{2} \cos ^{2} \varphi+z^{2}\left(1-\frac{1}{m^{2}} M_{t}^{2} \cos ^{2} \varphi\right)\right)\left(\left(1-\frac{1}{m^{2}} M_{t}^{2} \cos ^{2} \varphi\right)^{\frac{1}{2}}\left(1-\frac{1}{2} M_{t}^{2} \cos ^{2} \varphi\right)+\left(1-M_{t}^{2} \cos ^{2} \varphi\right)^{\frac{1}{2}}\right)} \\
& M_{t}=\frac{v}{\sqrt{\frac{\mu}{\rho}}} ; m=\sqrt{\frac{\lambda+2 \mu}{\mu}}
\end{aligned}
$$

Georgidis and Lykotrafitis (42) give the vertical displacement $\mathrm{w}_{\mathrm{s}}(\mathrm{d})$ of a point located at the surface, with polar coordinates $(\mathrm{d}, \varphi)$ from the applied load, $\varphi=0$ corresponding to the $\mathrm{y}=0$ plane. Note that the result can also be found in (43) (44):

$$
w_{S}(d)=-\frac{P}{\pi \mu d} \frac{\left(1-\frac{1}{m^{2}} M_{t}^{2} \sin ^{2} \varphi\right)^{1 / 2}\left(\left(2-M_{t}^{2} \sin ^{2} \varphi\right)^{2}+4\left(1-\frac{1}{m^{2}} M_{t}^{4} \sin ^{4} \varphi\right)^{1 / 2}\right)}{M_{t}^{6} \sin ^{6} \varphi-8 M_{t}^{4} \sin ^{6} \varphi+8 M_{t}^{2} \sin ^{2} \varphi\left(3-\frac{2}{m^{2}}\right)-16+\frac{16}{m^{2}}}
$$

If the point is on the $\mathrm{x}$-axis, $\varphi=0$ and the above formula gets much simpler:

$$
w_{S}(d)=\frac{P}{2 \pi \mu d} \frac{\lambda+2 \mu}{\lambda+\mu}
$$

The simulation in the mobile referential, with the boundary conditions considered here, corresponds to the response of the ground to an infinite series of point loads, periodically distributed along the xdirection. The vertical displacement resulting from this periodic distribution of loads is then theoretically infinite. However, it is possible by superposition of the solutions given above, to evaluate the relative vertical displacement between two points within the considered domain (see for instance (45)). A superposition can be carried out numerically as the result of the computation of a series, in order to estimate the equivalent vertical displacement. In practice, the first twenty terms of the series are sufficient to get an estimate of the result.

We recall here the different wave velocities (see for example (43)), $\mathrm{C}_{1}$ being the velocity of longitudinal waves and $\mathrm{C}_{2}$ the velocity of transversal waves: 
$C_{1}=\sqrt{\frac{\lambda+2 \mu}{\rho}} ; C_{2}=\sqrt{\frac{\lambda \mu}{\rho}}$

The Rayleigh velocity $C_{3}$ is the root of $G(V)$ such that $0<C_{3}<C_{2}$ with $\mathrm{G}$ defined by:

$G(V)=\left(2-\left(\frac{V}{C_{2}}\right)^{2}\right)^{2}-4 \sqrt{\left(1-\left(\frac{V}{C_{1}}\right)^{2}\right)\left(1-\left(\frac{V}{C_{2}}\right)^{2}\right)}$

To validate the numerical implementation presented above, a three-dimensional finite element simulation was performed, using the code CESAR-LCPC (see section 6) with a mesh of dimensions $\mathrm{L}_{\mathrm{w}} / 2 \times 5 \mathrm{~L}_{\mathrm{w}} \times 5 \mathrm{~L}_{\mathrm{w}}$. The boundary conditions set to zero :

- the displacement along $\mathrm{x}$ on the planes $\mathrm{x}=0$ and $\mathrm{x}=\mathrm{L}_{\mathrm{w}} / 2$

- the displacement along y on the plane $y=5 \mathrm{~L}_{\mathrm{w}}$

- all components of the displacement on the plane $\mathrm{z}=-5 \mathrm{~L}_{\mathrm{w}}$

Computations are performed for the following values of the numerical parameters:

$\mathrm{E}=75 \mathrm{MPa}, v=0.25$, (or equivalently $\lambda=30 \mathrm{MPa} \mu=30 \mathrm{MPa}$ ), $\rho=1800 \mathrm{~kg} \cdot \mathrm{m}^{-3}, \mathrm{~L}_{\mathrm{w}}=20 \mathrm{~m}$, $\mathrm{z}=1 \mathrm{~m}, \mathrm{P}=100 \mathrm{kN}$

For these parameters we have: $C_{1}=223.6 \mathrm{~m} / \mathrm{s} ; C_{2}=129.1 \mathrm{~m} / \mathrm{s} ; C_{3}=118.7 \mathrm{~m} / \mathrm{s}$.

The mesh is shown in Figure 4: it comprises 41000 nodes and 15000 quadratic (pentahedra) elements. The size of the elements varies between $50 \mathrm{~cm}$ and $10 \mathrm{~m}$.

Figure 5 compares the relative vertical displacements of points $\mathrm{A}$ and $\mathrm{B}$ for various values of the train speed $\mathrm{v}$, given by the analytical approach briefly presented above and by the finite element simulation. The very good agreement between the theoretical and numerical values validates the implementation of the simulation in a mobile referential in the numerical code.

\section{Application to a high speed railway MSE wall}

This section presents the results of the proposed approach application to a high speed railway. The effect of a high speed train passing on a MSE wall has been simulated with two sets of mechanical properties for the backfill material: one corresponding to typical materials used in practice, and the 
second corresponding to a less stiff material, in which the shear wave velocity is smaller. Simulations have been performed using the finite element software code CESAR-LCPC (46), in which the appropriate modification have been implemented to take into account the mobile referential.

\subsection{Geometry}

We first define the geometry of the wall. The cross section is described in Figure 6. As explained earlier, the extent of the domain taken into account, along the motion direction, is equal to one half of the distance $\mathrm{L}$ between two bogies. In practice, we adopt the value $\mathrm{L}_{\mathrm{w}}=18.7 \mathrm{~m}$, which corresponds to a Thalys train (between Paris and Amsterdam or Brussels for instance).

The mesh used for the simulations is also presented in Figure 6. It comprises 35000 nodes and 10000 quadratic elements (20-node hexahedra and 15-node pentahedra).The facing is made of 14-cm thick concrete panels.

\subsection{Steps of the simulation}

The simulation is carried out in two steps:

- The first step is a static computation, in which the construction of the wall is simulated by activating successively five layers of backfill (in the reinforced and in the unreinforced zones) and the corresponding parts of the facing, then the sub-ballast and ballast layers (the activation consists of taking into account the contribution of the elements to the overall stiffness matrix, and in applying their self-weight). The contact between the facing and the backfill is taken into account by means of a thin layer of elements with an elastic behaviour, making it possible to account for the slippage of the backfill material behind the facing during the construction process; this first step is used to define the initial stress field for the second step, which simulates the passing of a train (in the mobile referential).

- In the second step, we apply the pressure distribution corresponding to the load brought by the axles on the ballast layer, taking into account the modified stiffness matrix which depends on the train speed, according to Eq. (10) and Eq. (40). 


\subsection{Loads and boundary conditions}

The boundary conditions are given by Eq. (15) on the symmetry planes, and the displacement is set to zero on the basis of the mesh.

Two wheels of the same axle apply a $90 \mathrm{kN}$ load on the structure. This load is applied at a distance of $1.5 \mathrm{~m}$ of the bogie plane of symmetry, and is spread over a certain area. According to (47), this load is distributed over seven sleepers located on either side of the wheels, with coefficients that account for the rail vibrations and the railway structure damping. In practice, we take into account the effect of both axles of the bogie, and apply non uniform pressures at the top of the embankment, on an area corresponding to 7 sleepers. Since the aim of our study is to discuss the influence of the train speed, we have not undertaken to discuss precisely the influence of the assumptions made to assess these nonuniform pressures.

\subsection{Material parameters}

As the aim of the simulation is to discuss the influence of the train speed, we have chosen to adopt simple constitutive laws for all constituents of the structure. Especially, the ballast is treated as a continuous isotropic material, which is a strong approximation, with a Mohr-Coulomb plastic law (38). The same choice is made for the sub-ballast layer and the backfill material.

For the ballast (see Table 1), we have adopted values derived from the results of the European research project Innotrack, carried out between 2006 and 2009 (48).

For the backfill material, we have tested two values of the Young's modulus. The first one corresponds to "typical" values of the modulus of a railway backfill, obtained on a full-scale experimental MSE wall (38) (49). The second value corresponds to a less stiff material, in which the shear wave velocity is lower, which is why it is referred to as a "slow backfill material" in the following. 


\subsection{Results and discussion}

We only discuss the results of the second step of the simulation, the results of the first step being similar to those already presented in (18).

In the mobile referential, the variations of all quantities along the direction of the motion are directly related with the time variations before, during and after the train passing.

\section{$\underline{\text { Displacements }}$}

We first present the vertical displacements, at mid-distance between the rails (i.e. at a distance of $3 \mathrm{~m}$ from the facing), and at the level of the limit between the ballast and the sub-ballast layer, along the direction of the rails. Figure 8 shows the results obtained, for a static load and for a train passing at different speeds, for the typical backfill stiffness and for the slow embankment.

For the typical backfill material, the maximum vertical deflection is in the order of $0.4 \mathrm{~mm}$ for a static load (i.e. a train at a speed equal to 0 ), and is increased by $11 \%$ for a speed of $350 \mathrm{~km} / \mathrm{h}$.

For the slow backfill material, the maximum deflection for a static load is larger, around $1.2 \mathrm{~mm}$. The relative increase in maximum deflection computed for a speed of $350 \mathrm{~km} / \mathrm{h}$ is now of $44 \%$. It is worth noting that the deflection at the plane of symmetry $(x=0)$ is reduced with respect to the static case, showing that the mobile load induces a concentration of the deformation under the wheel, which reflects the fact that the train speed gets close to the velocity of Rayleigh waves in the backfill.

Note also that there is a zone, ahead of the wheel position, where the embankment exhibits an uplift of approximately $0.2 \mathrm{~mm}$. For $v=0.5$ (incompressibility) the sinking under the load must be compensated by an uplift. This uplift appears to depend largely on the speed. Some observations confirm this phenomenon (50).

In the last place, it can be noted that, even if the relative increase in the maximum deflection may seem large, the absolute values of the deflection remain small, a few tenths of millimeters in the case of the typical backfill material, and a little less than $2 \mathrm{~mm}$ for the slow backfill material. Such displacements are not likely to have a significant influence on the stability of the wall. 


\section{Tensile forces in the strips}

The multiphase approach makes it possible to evaluate the tensile forces in the strips (this is done by multiplying the uniaxial stress in the reinforcement phase $n^{r}$ by the area associated with each strip, i.e. the total area of the facing divided by the total number of strips). In the case of the typical backfill material, there is practically no influence of the train speed on the results. The results obtained for the slow backfill material are shown in Figure 9, for a strip that would be located in the upper part of the wall $(\mathrm{z}=3.75 \mathrm{~m})$. For a static load (train speed equal to zero), the value of the tensile force is minimal at mid-length of a train car. For a train speed of $350 \mathrm{~km} / \mathrm{h}$, the minimum value of the tensile forces is also attained at mid-length of the train car, but the minimum value is larger, showing that the train speed is too large to let the tensile forces get back to their initial value.

It can be noticed that the variations in the tensile forces induced by the load (static or in motion) are not negligible with respect to the initial tensile forces obtained at the end of the wall construction.

\section{Vertical stresses in the backfill material}

For the typical backfill material, the vertical stresses variations induced by the load are not influenced by the train speed (in the range $0-350 \mathrm{~km} / \mathrm{h}$ ). For a slow embankment, the distribution of the vertical stress along the train is different for a static load and for a train moving at $350 \mathrm{~km} / \mathrm{h}$. Figure 10 shows the variations of the vertical stress in the backfill computed at the level of the upper row of strips $(\mathrm{z}=3.75 \mathrm{~m})$. The maximum vertical stress below the wheel is $30 \%$ larger for a speed of $350 \mathrm{~km} / \mathrm{h}$ than for a static load. Note that this increase in vertical stress on the backfill-strip interface results in an increase in the shear strain that can be mobilized at this interface, and is therefore not necessarily adverse to the internal stability of the MSE wall.

\section{$\underline{\text { Relative displacement between the matrix and the reinforcement phases }}$}

As mentioned before, the multiphase model involves the relative displacement between the backfill material (matrix phase) and the strips (reinforcement phase), along the direction of the strips, denoted above by $U_{y}^{m}-U_{y}^{r}$. The simulation gives access to the variations of this relative displacement. The 
relative displacement is, in all cases, less than $30 \mu \mathrm{m}$. Even if no experimental data are available to validate this result, the order of magnitude does not seem unrealistic. The small value obtained makes it unlikely that significant fatigue phenomena occur as a result of numerous passing trains, but this assertion remains to be discussed, on the basis of the relative displacement obtained here and from a model, that remains to be elaborated, able to describe the effect of the accumulation of cycles in which the relative displacement varies.

\section{Conclusion}

We have proposed a three dimensional finite element analysis of the effects of a high speed train passing on a MSE wall. The approach presents two original features: the computation is carried out in a referential attached to the mobile load, and the reinforced backfill material is modeled using the multiphase model.

It is worth noting that the approach is extremely efficient from a numerical point of view, for two main reasons:

- in the first place, the computational effort required is the same as for a single static analysis. Since no time discretization is performed, the computation time is roughly divided by the number of time steps that would have been needed if we had used a direct time integration scheme.

- also the assumptions made on the periodicity of the loads brought by the axles and the symmetries reduce the domain taken into account in the analysis, and make it possible to use a relatively small mesh, the total number of degrees of freedom being around 120000 .

Results show that, for a backfill material with typical mechanical properties, the speed of the load has a relatively small influence on the various parameters we have analyzed: vertical displacements, vertical stresses in the backfill, tensile forces in the strips, etc. The maximum vertical deflection is increased, at the bottom of the ballast layer, by approximately $11 \%$, but the stresses in the reinforced backfill and the tensile forces in the strips are almost the same as those obtained for a static load. For a "slow" backfill material, the influence of speed is clearer. When the train speed gets close to the shear wave velocity, 
the simulation shows an amplification of the vertical displacements and of the vertical stresses in the backfill which is concentrated below the wheel. The strips of the upper part of the wall are submitted to a tensile force larger than the initial one over the whole length of the train and not only below the bogie. This type of result is consistent with those of Paolucci and Spinelli (51) or Hall (52) for instance, when the train speeds is close to the velocity of Rayleigh waves.

Such dynamic effects tend to modify the ratio between the shear stress and the normal stress along the strips, which remains nevertheless similar to that obtained for a static load.

In the last place, the model could be improved in at least two points: the first one consists in taking into account the role of material damping, in a way consistent with the mobile referential approach. The second one is relative to the choice of the parameter describing the mechanical interaction between the phases of the multiphase model.

\section{References}

1. Vidal, H. La Terre Armée. Annales de l'Institut Technique du Bâtiment et des Travaux Publics. 1966, 223-224, pp. 890-938.

2. Gedney DS, McKittrick DP. Reinforced Earth: A New Alternative for Earth Retention Structures. Civil Engineering-ASCE. 1975, Vol. 45, 10, pp. 58-61.

3. Vidal H. The Development and Future of Reinforced Earth. Symposium on Earth Reinforcement, Pittsburgh, Pennsylvania. 1978, pp. 1-61.

4. Schlosser F, Segrestin P. Local stability analysis method of design of reinforced earth structures. C. R. Coll. Int. Renforcement des Sols, Paris. 1979, pp. 157-162.

5. Juran I, Chen CL. Strain Compatibility Design Method for Reinforced Earth Walls. Journal of Geotechnical Engineering. 1988, Vol. 115, 4, pp. 435-456.

6. Bathurst RJ, Huang B, Allen TM. Load and resistance factor design (LRFD) calibration for steel grid reinforced soil walls. Georisk. 2011, Vol. 5, (3-4), pp. 218-228. 
7. Yu Y, Bathurst RL, Miyata Y. Numerical analysis of a mechanically stabilized earth wall reinforced with steel strips . Soils and Foundations. 2015, Vol. 55, 3, 536-547.

8. Anderson HW, Dodd JS. Element method applied to rock mechanics. Proc. of the 1st Congress Int. Soc. of Rock Mech., Lisbon. 1966.

9. Bergado DT, Lo KH, Chai J-C,Shivashankar R, Alafaro MC, Anderson LR. Pullout Tests using Steel Grid Reinforcements with Low-Quality Backfill. Journal of Geotechnical Engineering. 1992, Vol. 118, 7, pp. 1047-1063.

10. de Buhan $\mathbf{P}$, Salençon J. Analyse de stabilité d'ouvarges en sol renforcé. Proceedings of the 11th International Conference on Soil Mechanics and Foundation Engineering, San Francisco, August 12-16. 1985, pp. 1749-1752.

11. Harrison WJ, Gerrard CM. Elastic theory applied to reinforced earth. J. of the Soil Mech. and Found. Div. ASCE. 1972, Vol. 98, 12, pp. 1325-1345.

12. Gerrard CM. Reinforced soil: an orthorhombic material. J. Geotech. Engng. Div. ASCE. 1982, Vol. 11, pp. 1460-1474.

13. Chang JR, Forsyth RA. Finite Element Analysis of Reinforced Earth Wall. J. Geotech. Engng. Div. ASCE. 1977, Vol. 103, 7, pp. 711-724.

14. de Buhan P, Hassen G. Multiphase approach as a generalized homogenization procedure for modelling the macroscopic behavior of soils reinforced by linear inclusions. European Journal of Mechanics A/Solids. 2008, Vol. 27, pp. 662-679.

15. de Buhan P, Sudret B. Micropolar multiphase model for geomaterial reinforced by linear inclusions. European Journal of Mechanics A/Solids. 2000, Vol. 19, 6, pp. 669-687.

16. Bourgeois E, de Buhan P, Hassen G. Settlement analysis of piled-raft foundations by means of a multiphase model accounting for soil-pile interactions. Computers and Geotechnics. 2012, Vol. 46, pp. 26-38. 
17. Bourgeois E, de Buhan P, Hassen G. Finite element simulations of the behavior of piled raft foundations using a multiphase model. International Journal for Numerical and Analytical Methods in Geomechanics. 2013, Vol. 37, pp. 1122-1139.

18. Bourgeois E, Le Kouby A, Soyez L. Influence of the strip-backfill interaction model in the analysisof the behavior of a mechanically stabilized earth wall. Soils and Foundations. 2012, Vol. 52, 3, pp. 550-561.

19. Chau TL, Bourgeois E, Corfdir A. Finite element analysis of the effect of corrosion on the behavior of reinforced earth walls. International Journal for Numerical and Analytical Methods in Geomechanics. 2012, Vol. 36, 15, pp. 1741-1756.

20. Nguyen VT, Hassen G, de Buhan P. Assessing the dynamic stiffness of piles-raft foundations by means of a multiphase model. Computers and Geotechnics. 2016, Vol. 71, pp. 124-135

21. Bettess, P. Infinite elements. Sunderland : Penshaw Press, 1992.

22. Semblat JF, Pecker A. Waves and vibrations in soils: Earthquakes, Traffic, Shocks, Construction work. Pavia : UISS Press, 2009.

23. Auersch, L. The excitation of ground vibration by rail traffic: theory of vehicle-track-soil interaction and measurements on high-speed lines. Journal of Sound and Vibration. 2005, Vol. 284, 1-2, pp. 103-132.

24. Andersen L, Augustesen A H. Mitigation of traffic-induced ground vibration by inclined wave barriers- A three-dimensional numerical analysis. The Sixteenth International Congress on Sound and Vibration. 2009.

25. Payeur JB, Corfdir A, Bourgeois E. Dynamic behavior of a Mechanically Stabilized Earth under harmonic loading: Experimental characterization and 3D finite elements model. Computers and Geotechnics. 2015, Vol. 65, pp. 199-211. 
26. Soyez, L. Contribution à l'étude du comportment des ouvrages en sol renforcé soumis à dse charges d'expoitation ferroviaire (charges dynamiques et cycliques). Marne-la-Vallée (France) : Ecole nationale des Ponts et chaussées, 2009. (PhD thesis).

27. Picoux B, Le Houedec D. Diagnosis and prediction of vibrations from railway trains. Soil Dynamics and Earthquake Engineering. Vol. 25, 12, pp. 905-921.

28. Chupin O, Piau JM. Modelling the dynamic response of a multilayered railway structure under a moving load. 20ème Congrès Français de Mécanique, Besançon. 2011.

29. Picoux B, Rotinat R, Regoin JP, Le Houedec D. Prediction and measurements of vibrations from railway track lying on a peaty ground. Journal of Sound and Vibration. 2003, Vol. 267, 3, pp. 575-589.

30. Jones CJC, Sheng X, Petyt M. Simulations of ground vibration from a moving load on a railway track. Journal of Sound and Vibration. 2000, Vol. 231, 3, pp. 739-751.

31. Chahour K, Lefeuve-Mesgouez G, Mesgouez A,. Spectral analysis of a railway track in contact with a multilayered poroviscoelastic soil subjected to a harmonic moving load. Soil Dynamics and Earthquake Engineering. 2014, Vol. 64, pp. 24-37.

32. Celebi E, Schmid G. Investigation of ground vibrations induced by moving loads. Engineering Structures. 2005, Vol. 27, pp. 1981-1998.

33. Zhai W, Song E. Three dimensional FEM of moving coordinates for the analysis of transient vibrations due to moving loads. Computers and Geotechnics. 2010, Vol. 37, pp. 164174.

34. Shi L, Selvadurai APS. Dynamic response of an infinite beam supported by a saturated poroelastic halfspace and subjected to a concentrated load moving at a constant velocity. International Journal of Solids and Structures. 2016, Vol. 88-89, pp. 35-55.

35. O'Brien J, Rizos DC. A 3D BEM-FEM methodology for simulation of high speed train induced vibrations. Sol Dynamics and Earthquake Engineering. 2005, Vol. 25, pp. 289-301. 
36. Hanazato T, Ugai K, Mori M, Sakaguchi R. Three-Dimensional Analysis of TrafficInduced Ground Vibrations. Journal of Geotechnical Engineering. 1991, Vol. 117, 8, pp. 11331151.

37. Bian XC, Chen YM, Hu T. Numerical simulation of high-speed train induced ground vibrations using 2.5D finite element approach. Science in China Series G: Physics, Mechanics \& Astronomy. 2008, Vol. 51, 6, pp. 632-650.

38. Indraratna B, Thakur P, Vinod J. Experimental and Numerical Study of Railway Ballast Behavior under Cyclic Loading. International Journal of Geomechanics. 2010, Vol. 10, 4, pp. $136-144$.

39. Hassen G, Dias D, de Buhan P. Multiphase constitutive model for the design of piled embankments: comparison with three-dimensional numerical simulations. International Journal of Geomechanics. 2009, Vol. 9, 6, pp. 258-266.

40. Eason, G. The stresses produced in a semi-infinite solid by a moving surface force. International Journal of Engineering Science. 1965, Vol. 2, 6, pp. 581-609.

41. Mandel, J, Avramesco, A. Déplacements produits par une charge mobile à la surface d'un semi-espace élastique. Comptes-rendus des séances de l'Académie des sciences. 1961, Vol. 252, 3, pp. 3730-3732. (in French).

42. Georgidis HG, Lykotrafitis G. A Method Based on the Radon Transform for ThreeDimensional Elastodynamic Problems of Moving Loads. Journal of Elasticity. 2001, Vol. 65, pp. 87-129.

43. Barber, JR. Surface displacements due to a steadily moving point force. ASME Journal of Applied Mechanics. 1996, Vol. 63, pp. 245-251.

44. Churilov, VA. On the effect of a normal load moving at a constant velocity along the boundary of an elsatic half-space. Journal of Applied Mathematics and Mechanics. 1977, Vol. 41 , pp. $125-132$. 
45. Corfdir A, Bonnet, G. Validity conditions of direct boundary integral equation for exterior problems in plane elasticity. Comptes-Rendus de Mécanique. 2007, Vol. 335, pp. 219-224.

46. Humbert P, Dubouchet A, Fezans G, Remaud D. CESAR-LCPC: A computation software package dedicated to civil engineering uses. Bulletin des laboratoires des ponts et chaussées. Vol. 256-257, pp. 7-37.

47. Manzanas J, Moreno J, Cuellar V, Andreu MA, Navarro F. CEDEX's experimental facility for testing railway tracks. XIV European Conference on Soil Mechanics and Geotechnical Engineering, Madrid. 2007, pp. 2037-2055.

48. INNOTRACK. Deliverable 2.1.16 Final report on the modelling of poor quality sites. 2009.

49. Bourgeois E, Soyez L, Le Kouby A. Experimental and numerical study of the behavior of a reinforced earth wall subjected to a local load. Computers and Geotechnics. 2011, Vol. 38, pp. 515-525.

50. Cui Y-J, Lamas-Lopez F, Trinh VN, Calon N, Costa D’Aguiar S, Dupla J-C, Tang AM, Canou J, Robinet A. Investigation of interlayer soil behaviour by field monitoring. Transportation Geotechnics. 2014, Vol. 1, pp. 91-105.

51. Paolucci R, Spinelli D. Ground Motion Induced by Train Passage. Journal of Engineering Mechanics. 2006, Vol. 132, 2, pp. 201-210.

52. Hall L. Simulations and analyses of train-induced ground vibrations in finite element models. Soil Dynamics and Earthquake Engineering. 2003, Vol. 23, 5, pp. 403-413. 
Table 1 Values of material parameters

\begin{tabular}{|l|c|c|c|c|c|}
\hline & $\begin{array}{c}\gamma \\
\left(\mathrm{kN} / \mathrm{m}^{3}\right)\end{array}$ & $\mathrm{E}(\mathrm{MPa})$ & $v(-)$ & $\mathrm{c}(\mathrm{kPa})$ & $\varphi\left(^{\circ}\right)$ \\
\hline Ballast & 17 & 60 & 0.2 & 10 & 36 \\
\hline Sub-ballast layer & 23.3 & 90 & 0.3 & 10 & 36 \\
\hline « Slow» backfill material & 21 & 70 & 0.3 & 10 & 36 \\
\hline Typical backfill material & 21 & 150 & 0.3 & 10 & 36 \\
\hline Backfill / facing contact & 20 & 0.1 & 0.49 & - & - \\
\hline Concrete facing panels & 25 & 25000 & 0.2 & - & - \\
\hline
\end{tabular}




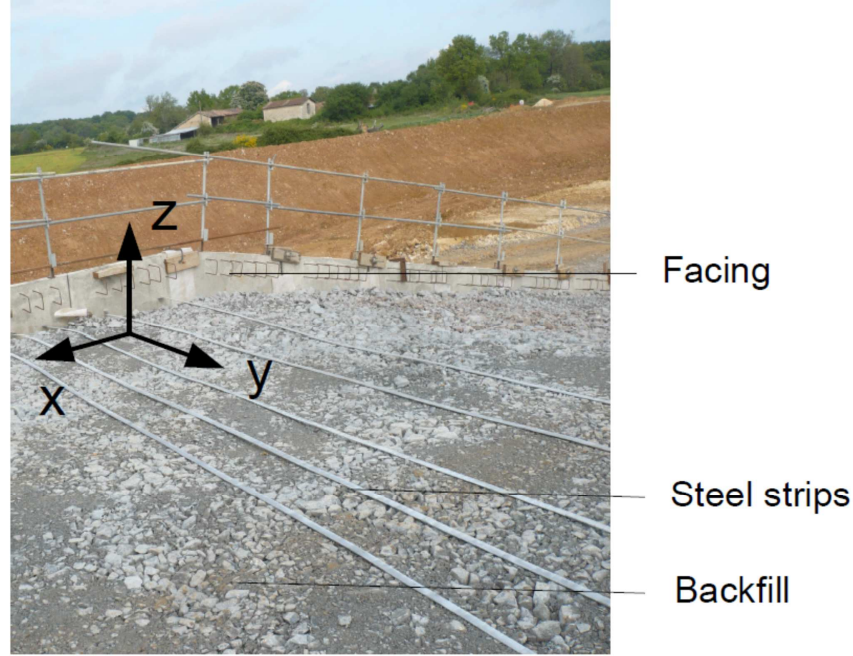

Figure 1- Picture taken during the construction of a MSE wall 


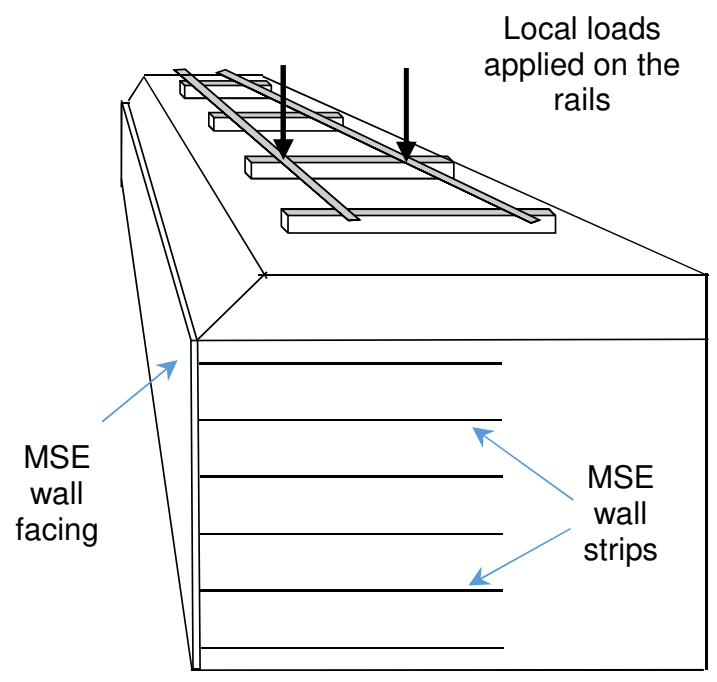

Figure 2 a) Schematic of a railway resting on a MSE wall

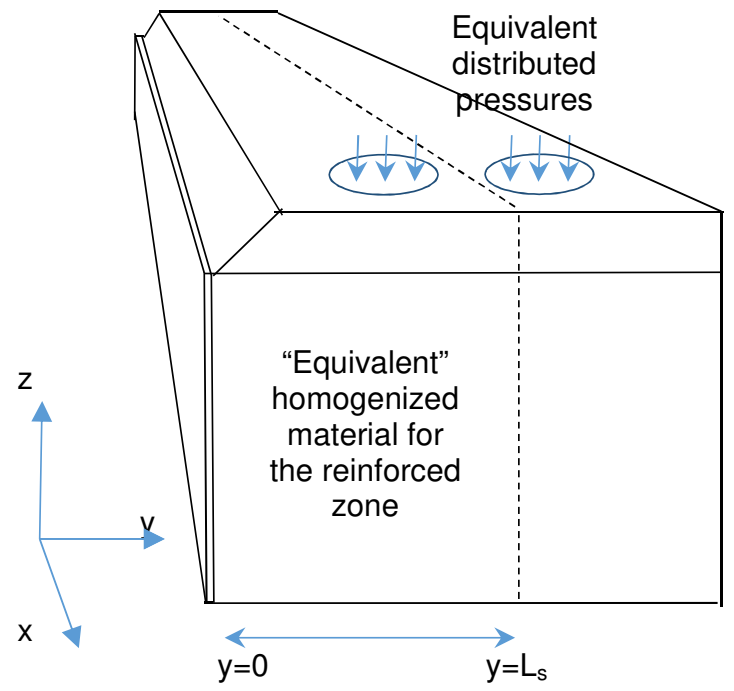

b) Proposed model 

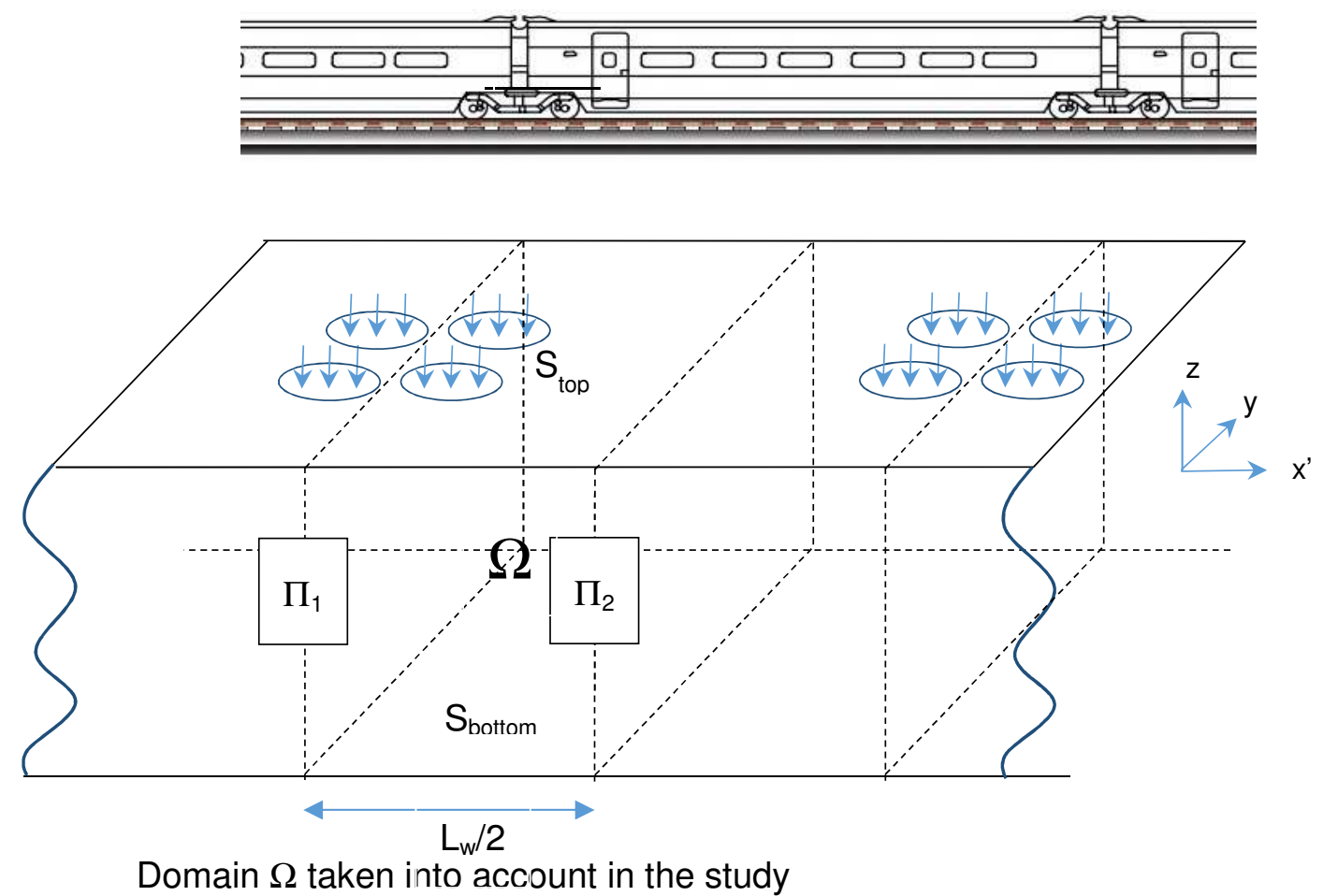

Figure 3 - Use of symmetries for an infinite and periodic train 

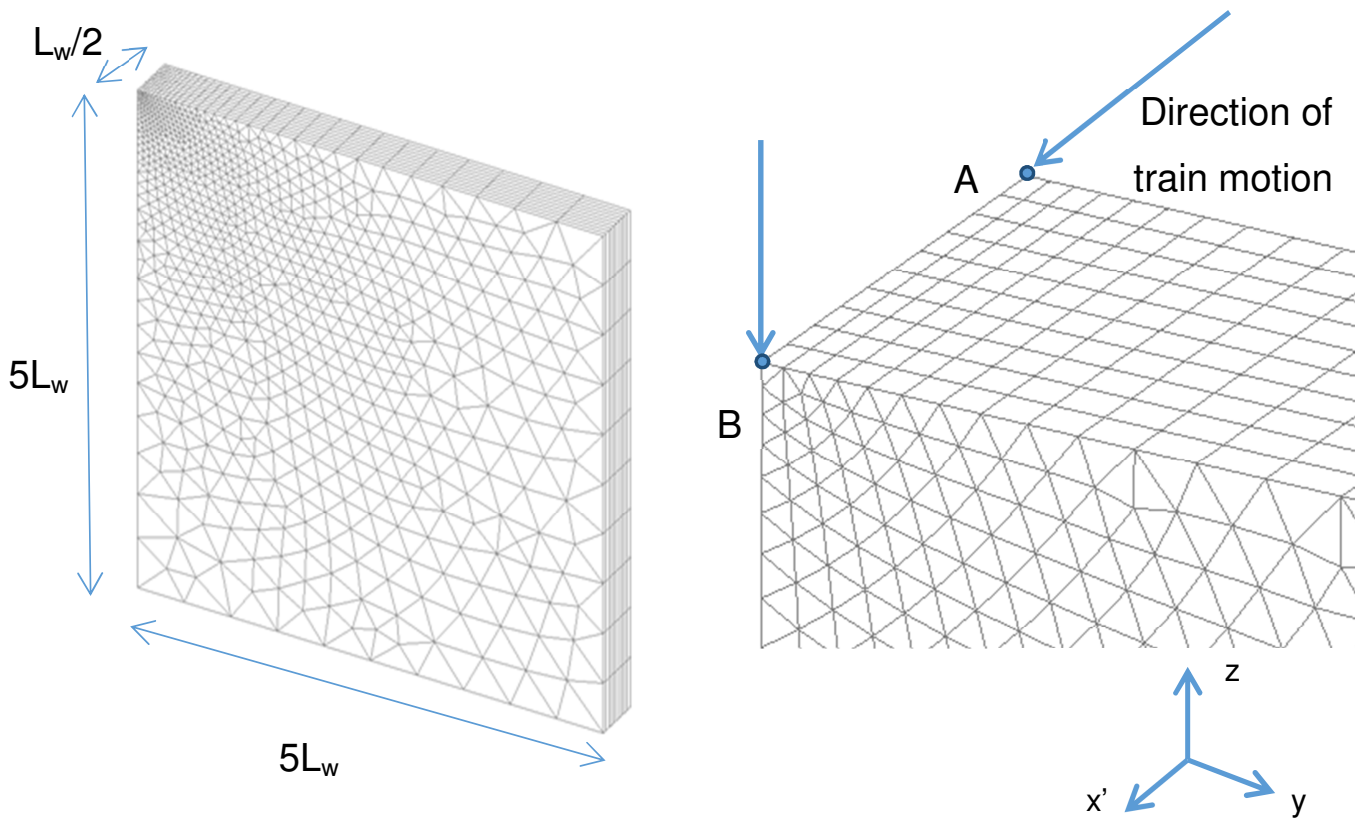

Figure 4 - Mesh used for the three-dimensional finite element simulation (left : general view ; right : close-up on the zone where the load is applied and definition of points $A$ and $B$ ). 


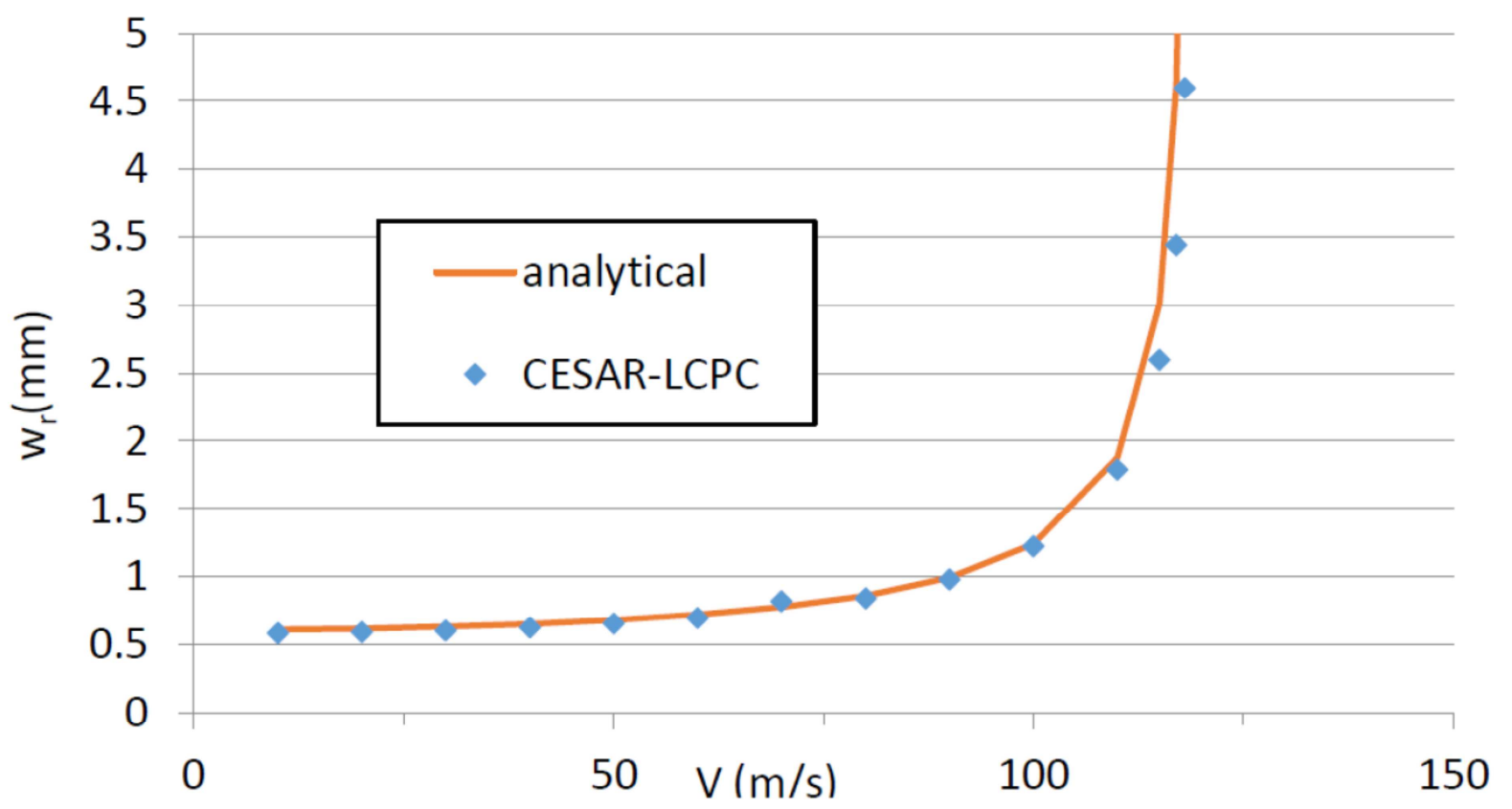

Figure 5 Evaluation of the relative vertical displacements between points $A$ and $B$ 


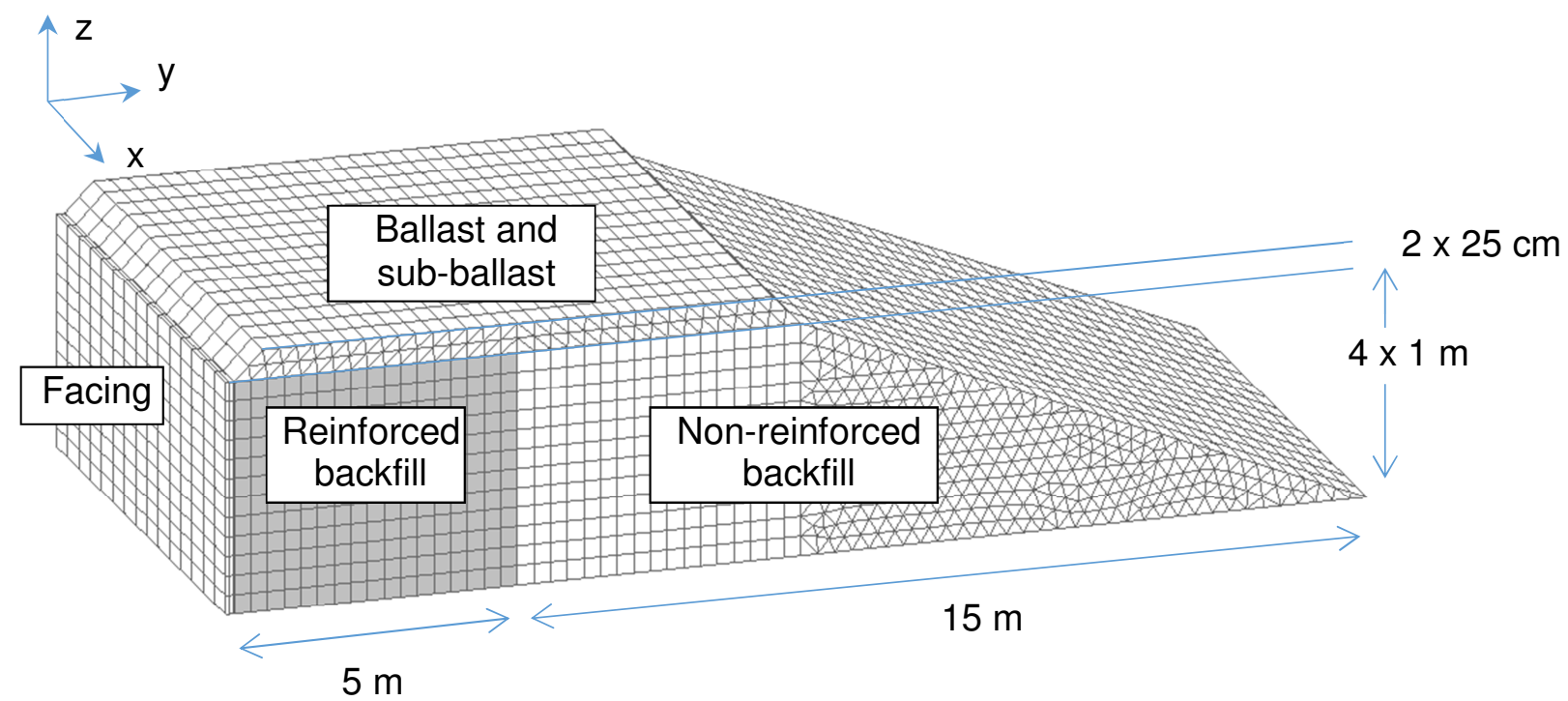

Figure 6-Geometry and mesh used for the three-dimensional finite element simulation 


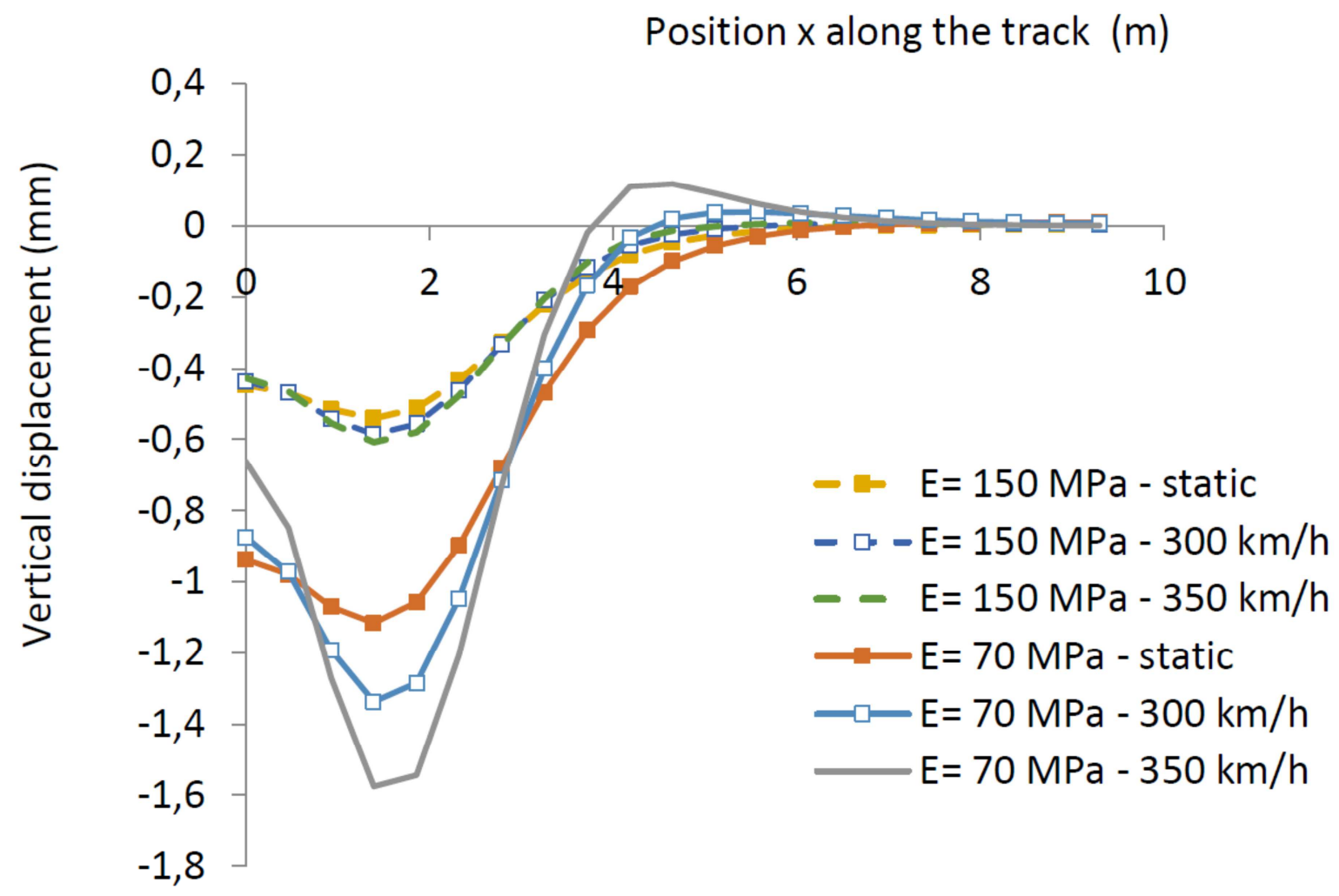

Figure 7 Vertical displacements at the bottom of the ballast layer according to the position $x$ 


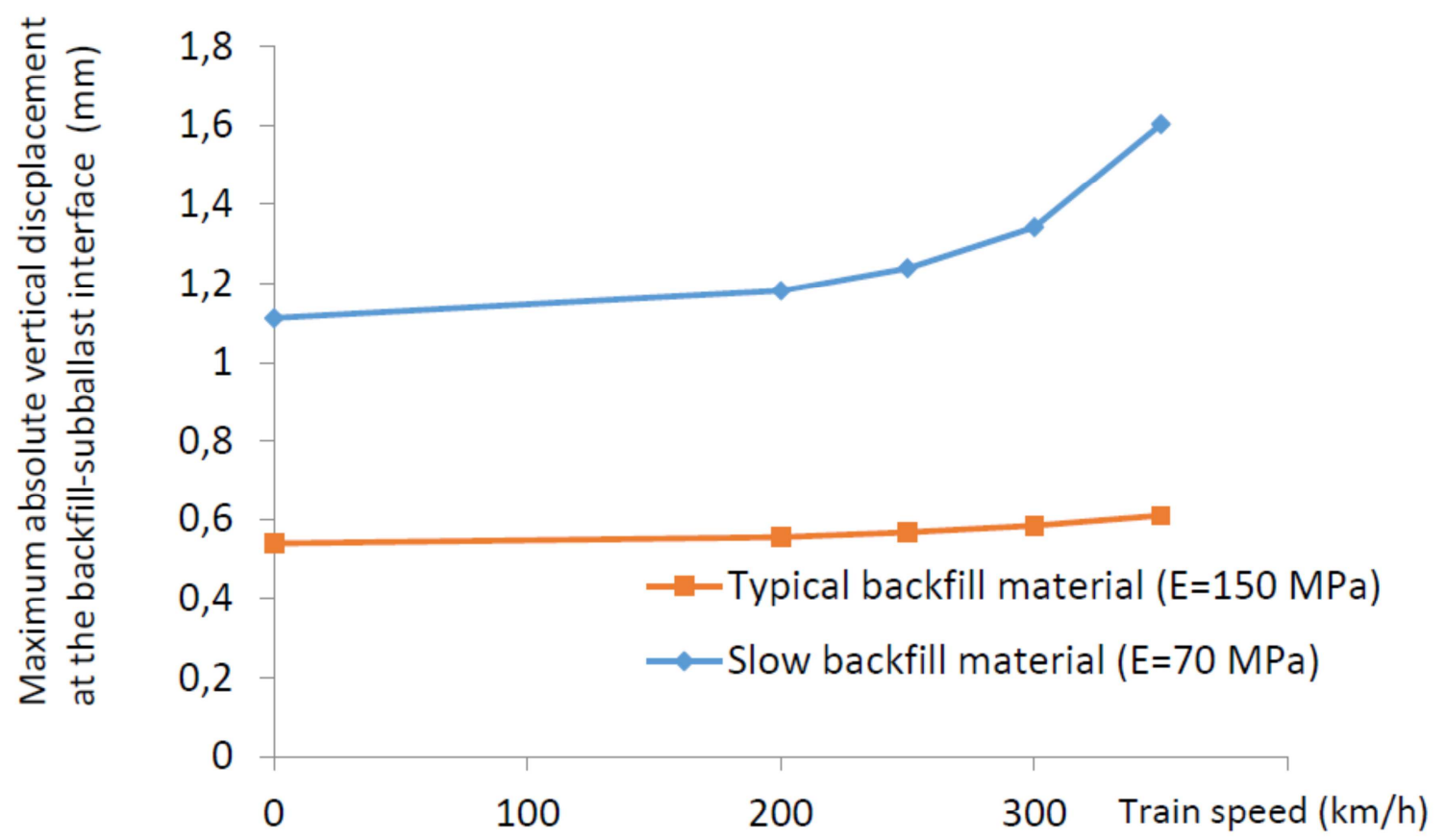

Figure 8- Maximal vertical displacements at the backfill-subballast Interface 


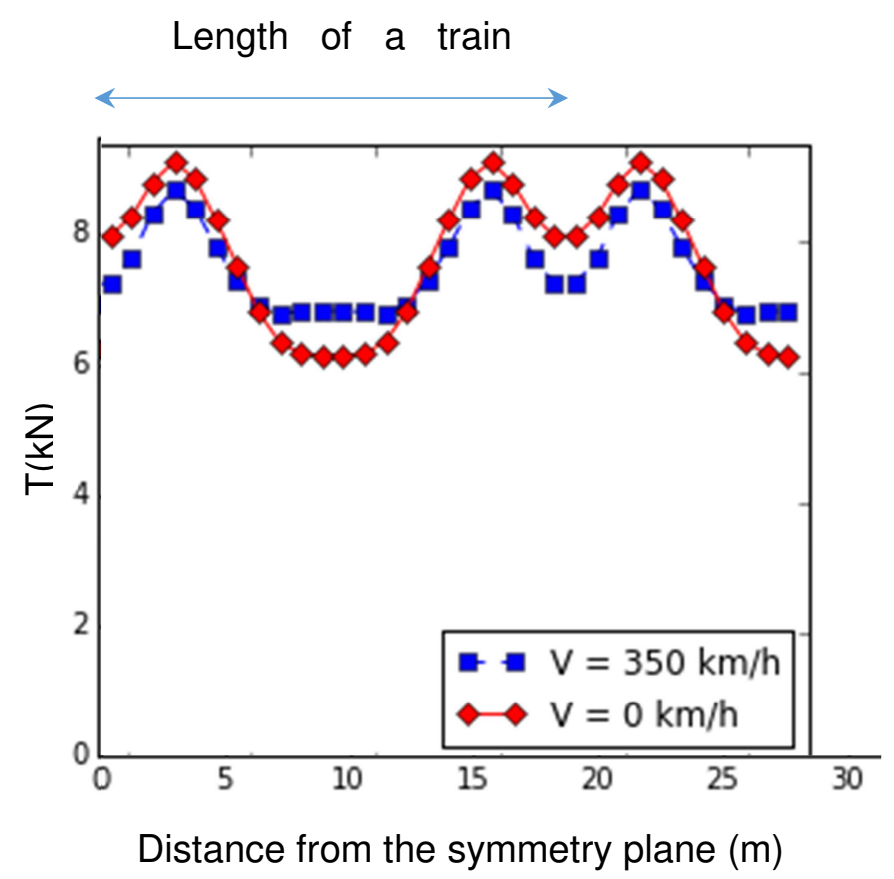

Figure 9Tensile forces in the strips along the train $(z=3.75 \mathrm{~m})$ 


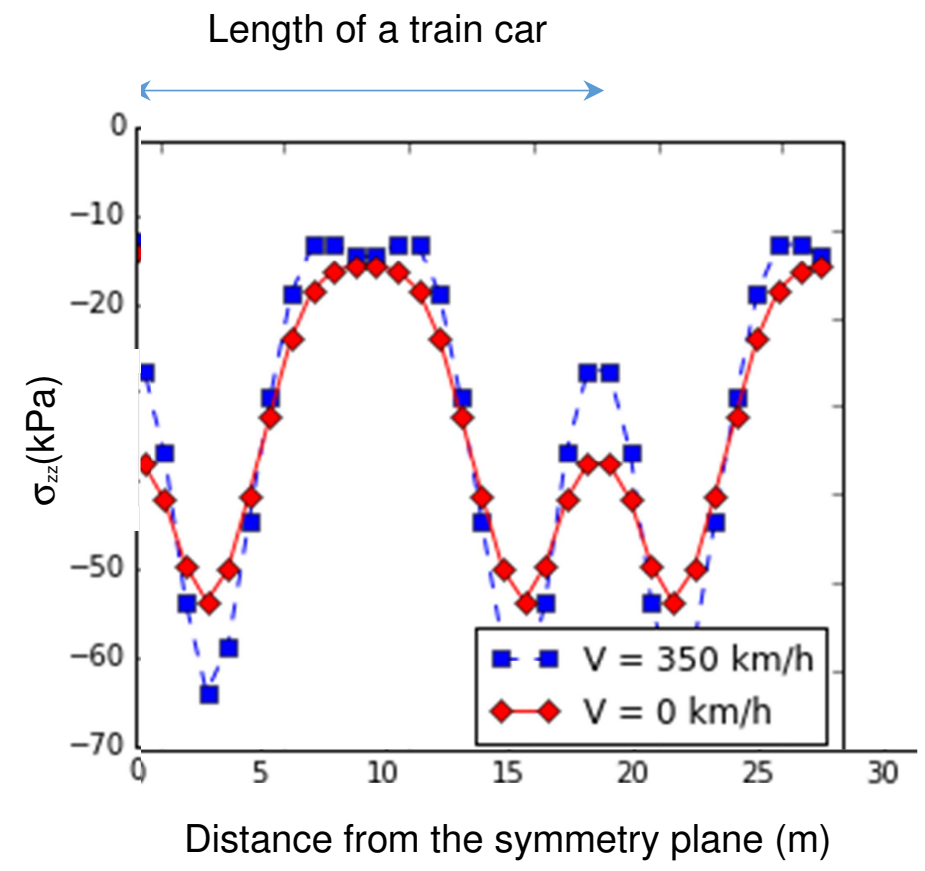

Figure 10 - Vertical stress below the train (at $z=3.75 \mathrm{~m}$ and $2.5 \mathrm{~m}$ away from the facing) 